\title{
Estimating the influence of accounting variables change on earnings management detection
}

\author{
Igor Pustylnick \\ Far Eastern Federal University \\ Vladivostok, Russia \\ Conestoga College \\ Kitchener, Canada \\ igorpustylnick@botmail.com \\ Oksana Temchenko \\ Far Eastern Federal University \\ Vladivostok, Russia \\ temchenkooksana@yandex.ru

\section{Sergey Gubarkov} \\ Far Eastern Federal University \\ Vladivostok, Russia \\ gsv20031973@mail.ru
}

Abstract. Standard earnings management detection is performed using two routes: real earnings management (connected with inventory and expenses manipulations) and accrual earnings management (connected with revenue and accounts receivables manipulations). Neither of these two detection algorithms attempts to quantify earnings management and connect it with the infractions committed by the companies, charged by the regulator (in this case - U.S. SEC). In many known cases of revenue manipulation, it is not possible to say whether real or accrual based earnings management was used. In this research, we look at the cases of financial statement fraud, namely one of the most common variations - revenue manipulation, from the perspective of the practitioner and propose the way of detection and quantification of such manipulations. In order to distinguish the cases of earnings management, we use the components of DuPont formula. In addition, we also look at the accounting variables used in the calculation of the detection criterion and determine which ones of them play the main role in revenue manipulations.

Keywords: earnings management, revenue manipulation, DuPont analysis, financial statement fraud, expenses manipulation, accruals manipulations.

JEL Classification: G31, M33 


\section{INTRODUCTION}

The phenomenon of earnings management is treated differently in various parts of the world and by professionals of various occupations. In this research, we view earnings management as a process of altering financial bottom line via artificially changing revenues and expenses figures (Bruns \& Merchant, 1990). The goal of the research, presented here, was to establish the mechanism of detecting earnings management and quantify its severity.

Accounting profession does not view earnings management as a punishable offence. Earnings management can be achieved by overproducing goods for sale, which company is not able to sell efficiently, and using absorption costing to reduce the value of costs of goods sold ${ }^{1}$. However, various accounting and financial scandals, happening at the turn of the $21^{\text {st }}$ century (Urri, 2002) have prompted several prominent accounting organizations in the North America, such as AICPA ${ }^{2}$ and $\mathrm{CICA}^{3}$, change their view on earnings management. According to Dechow and Skinner (2000) U.S. regulators changed their views on earnings management, which was followed by similar changes of position of German BAFIN ${ }^{4}$ (Achleitner, Günther, Kaserer, \& Siciliano, 2014) and several other European organizations (Lang, Smith Raedy, \& Wilson, 2006).

Earnings management detection research appears to be split between two different directions. One of them is Real Earnings Management (REM) detection, which deals with abnormal production expenses, estimations of cash flows from operations, estimating inventories and other measurable tangible activities (Roychowdhury, 2006). The second approach deals with the Accruals Based Earnings Management (ABEM), which attempts to detect abnormal changes in the accrual process (Dechow, Hutton, Kim, \& Sloan, 2012; Jones, 1991).

In our study, we attempt to merge both mentioned approaches basing on the assumption that the results of both types of earnings management can be equally present in financial statements of the reviewed organizations. We took the point of view that practitioners in the field of finance, investment or auditing view financial statements in their entirety and attempt to obtain a quick answer whether earnings management was present and whether it had influenced the values published in the reports under review.

Following the row of large financial scandals at the turn of the $21^{\text {st }}$ century, AICPA issued the new statement of auditing standards (SAS-99) (Marzcewski \& Akers, 2005), which described the moving forces of financial fraud. One of these moving forces was the desire to embellish financial performance by inserting false information into the financial records of the company (Lenard \& Alam, 2009). Such embellishment lead to fraud (Persons, 2011) or earnings management (Alexeev \& Kim, 2008), both accompanied by the decrease in liquidity for the observed firms.

In this research, we examined the role of liquidity as an indicator of the potential factor leading towards earnings management and the role of the financial indicators comprising the often-used DuPont formula. We show that the examination of liquidity-based financial variables and the indicators, used in the DuPont Formula, we can get a reasonably good indication whether the financial statements of a company include the results of earnings management, either ABEM, or REM, or both.

In the rest of the paper we will discuss the published developments in the field of earnings management detection, followed by the description of method and data, used in this research. We then discuss the

\footnotetext{
1 This is a very simple management accounting problem, which can be found in the basic management accounting textbooks, such as (Fess \& Warren, 1993)

2 American Institute of Certified Professional Accountants

3 Canadian Institute of Chartered Accountants

4 Bundesanstalt für Finanzdienstleistungsaufsicht
} 
obtained results and finish the paper with the conclusions and the description of potential limitations and the directions for future research.

\section{ANALYSIS OF PAST RESEARCH}

Examining the corporate effectiveness, according to managerial accounting requires two very important parameters, namely liquidity and efficiency (Austin, Haskins, Ferris, Sack, \& Allen, 2000). Altman (1968) defines a uniform score for measuring liquidity, also known as Z-Score. Sometimes described as measure of proximity to bankruptcy, Z-Score is used in a number of research efforts, among which are the works of (Taylor \& Xu, 2010), as well as (Park \& Shin, 2004), in connection with earnings management. The researchers show that low Z-Score is often recorded for the companies, which are also engaged in any form of earnings management (Ferrer \& Ferrer, 2016).

Bauman (2014) used DuPont formula to forecast changes in corporate profitability, which is in turn connected with corporate earnings. Jansen, Ramnath, and Yohn (2012) attempted to connect the phenomenon described in DuPont formula with earnings management. They introduced the connection between the rate of change of operating margin and the rate of change of asset turnover and connected them with the terms 'upward earnings management' and 'downward earnings management'.

While describing the earnings management, every researcher takes a slightly different view on the subject. McKee (2005) describes all different cases of earnings management from the managerial perspective and states that expenses play the most important role in forging earnings management cases. Dechow, Ge, Larson, and Sloan (2011) observe the changes in the corporate discretionary accruals and state that such abnormal changes can be a case of earnings management.

The research in REM and ABEM areas attempts to build the models with the coefficients, calculated for every firm over the period of observation (Achleitner et al., 2014; Dechow et al., 2011). This requires having the sample of firms with the entries from the financial statements over 10+ year span to achieve good model coverage. In many cases the practitioners in the finance and auditing field do not possess such historical information.

In the works of Spathis (2002) and Kirkos, Spathis, and Manopoulos (2007) the researchers are superimposing two samples of companies, one group charged with fraud with another group for which statements appear to be clean of signs of manipulations. The researchers conclude that the companies committing fraud have higher fluctuations of in the values of the gross margin in the adjacent years than the companies, statements of which appear clean. The researchers apparently found that companies were engaged in the earnings management, although the term may not have been in use in Greece at the time.

The described researchers as well as Beneish (1997) show that comparing the values of the chosen indicators in the adjacent years, whether alone or combined in the formula, such as M-Score (Beneish, 2001) will give a fair indication of the abnormal activities in these firms. By using such indicators Beneish, Press, and Vargus (2012) were able to detect earnings management in the financially distressed firms. Therefore, research question this paper is trying to address is "Is there are possibility to detect earnings management using a shorter time interval?"

According to Leggett, Parsons, and Reitenga (2016) real earnings management influences cash flow and operating earnings, whereas accrual earnings management influences predominantly revenues through manipulations with accounts receivable (Dechow, Sloan, \& Sweeney, 1995) and the valuation of the company (Alhadab, Clacher, \& Keasey, 2016). By further examination of the accounting variables involved 
in both real and accrual earnings management it is possible to see that the set of these variables is the same as the one used by Altman in calculating corporate liquidity ${ }^{5}$.

From the accounting perspective, signs of earnings management can appear in the financial statements through altering the amounts of earned revenue or through the changes of the values of incurred expenses (Beneish, 2001). If that is indeed the case, the view of Jansen et al. (2012) that the major sign of earnings management is different directions of change of operating margin and asset turnover ratios, must be always taken into account. Further exploring this point of view, it may be interesting to observe which parameter plays the prevalent role in determination of earnings management. This leads us to the following research question: "Knowing that earnings management exists and having an indicator of earnings management, is it possible to find what accounting variables play the most prominent role in it?"

\section{RESEARCH METHOD AND SAMPLE}

\section{Theoretical Model}

In order to answer our research questions, we will make the following assumption: "Under the stable industry conditions and stable mode of operations, the proportion of operating income in the revenue, also known as operating margin, does not fluctuate significantly between two adjacent years." This assumption is consistent with the findings of Tsipouridou and Spathis (2014) on earnings management in Greece.

If the proportion of variables does not change, it is possible to formulate that the difference of rates of change of these variables, calculated as

$$
\Delta V=\frac{V_{t}-V_{t-1}}{V_{t-1}}
$$

will be very close to zero. Here $V_{t}$ is the value of the variable in the current year and $V_{t-1}$ is the value of the same variable in the preceding year. In the scope of this research we take two variables, which are influenced mostly by accrual earnings management, such as Revenue and Shareholders Equity and two variables, which are influence predominantly by the real earnings management, i.e. Working Capital and Operating Income. In order to remove the effect of the size of the companies under review, we divide the values of all these variables by the value of total assets, thus creating these four variables:

$$
\begin{gathered}
X_{1}=\frac{\text { Working Capital }}{\text { Total Assets }} \\
X_{2}=\frac{\text { Operating Income }}{\text { Total Assets }} \\
Y_{1}=\frac{\text { Shareholders Equity }}{\text { Total Assets }} \\
Y_{2}=\frac{\text { Revenue }}{\text { Total Assets }}
\end{gathered}
$$

The variables, calculated by the by these formulas are then combined into the formulas, calculating the real liquidity of the organization $(\mathrm{R})$ and so-called perceived wealth $(\mathrm{P})$.

$$
\begin{gathered}
R=\alpha_{1} X_{1}+\alpha_{2} X_{2} \\
P=\beta_{1} Y_{1}+\beta_{2} Y_{2}
\end{gathered}
$$

${ }^{5}$ With the consideration that EBIT and Operating Income present very similar figures 
Here coefficients $\alpha_{\mathrm{i}}$ and $\beta_{\mathrm{i}}$ are calculated using discriminant analysis. The samples used in discriminant analysis are described further in this section. Using the formulas (3.1) and (3.2), we calculate the absolute values of variables $P$ and $R$. Then using formula (1) we calculate the rates of change $\Delta P$ and $\Delta R$ and calculate the difference in the rate of change $\Delta \mathrm{P}-\Delta \mathrm{R}$.

Using this analysis, we can formulate the following hypothesis: " $\Delta \mathrm{P}-\Delta \mathrm{R} \neq 0$ signifies the presence of earnings management. The positive difference corresponds to downward earnings management and negative corresponds to upward earnings management". The rejection of the corresponding null hypothesis will serve as answer to the research question whether it is possible to shorten the number of statements required to detect earnings management.

Pustylnik (1968) provides the method of checking of a certain event appears due to chance. According to this method, the probability of random number of occurrences of a certain event must lie within the interval

$$
\omega-u_{1-} p / 2 \sqrt{\frac{\omega(1-\omega)}{n}} \leq p \leq \omega+u_{1-} p / 2 \sqrt{\frac{\omega(1-\omega)}{n}}
$$

Here $u$ is a quantile of normal distribution with required significance, $\omega$ is the estimated random frequency and $n$ is the total number of observations. Having a frequency of occurrence lying outside of the specified interval will prompt the rejection of the null hypothesis. Here we check the number of the joint occurrences of upward/downward earnings management and $\Delta \mathrm{P}-\Delta \mathrm{R}$ appearing with the proper sign and use it as $\omega$. We also have a combined probability of two binary events, which would be $25 \%$.

In this work, we examine which accounting variables play the most important role in the increase of the absolute value of indicator of earnings management formulated in the methodology section. Determining this will allow auditors to concentrate on the certain areas of the financial statements (ex. Revenues vs. Expenses) in order to pinpoint the potential break of IFRS and GAAP rules.

Having a predictor variable and four relatively independent variables, the next step in the research is to build a model, which would connect these variables together. In the case of determination of potential for manipulations in the financial statements it is important to determine which variables influenced the outcome of the predictor variable.

The initial attempt was to build a linear regression model using predictor variable $\Delta \mathrm{P}-\Delta \mathrm{R}$ and four independent variables X1, X2, Y1, Y2. The model appeared extremely weak even with the elimination of the outlay values. $\mathrm{R}^{2}$ value did not exceed $20 \%$ for any of the cases. Therefore, building such model was considered impractical. As the next step, the values of the independent variables were substituted with the rate of growth of the independent variables, calculated by formula (1). The new model has been constructed based on the normalized predictor variables. This model is described by formula (5)

$$
\Delta P-\Delta R=\alpha_{1} \Delta V_{1}+\alpha_{2} \Delta V_{2}+\alpha_{3} \Delta V_{3}+\alpha_{4} \Delta V_{4}+\varepsilon
$$

here $\Delta \mathrm{V}_{1}$ rate of growth of $\mathrm{X}_{1}, \Delta \mathrm{V}_{2}$ rate of growth of $\mathrm{X}_{2}, \Delta \mathrm{V}_{3}$ rate of growth of $\mathrm{Y}_{1,} \Delta \mathrm{V}_{4}$ rate of growth of $\mathrm{Y}_{2}$. 


\section{Data Samples}

Data, used in this research, was obtained in the U.S. SEC EDGAR database. There are multiple reasons behind this decision. Firstly, the U.S. GAAP ${ }^{6}$ is very close the IFRS standard, which becomes a world-wide standard of financial information. Secondly, the database is electronic with the data stored in $\mathrm{XBRL}^{7}$ and is open to retrieval of data for the independent research. Thirdly, the sample of financial data in EDGAR is considered as one of the largest in the world, which is beneficial for any statistical research endeavor.

There are two main samples of data, used in this work.

1. The sample of companies, which were charged by the U.S. SEC with revenue manipulations. There are 31 companies in the sample and for each one of them we extracted the data for five years of operation. Most of the data was extracted manually since the infractions occurred prior to the mandatory XBRL based submissions of financial statements. The enforcement releases of U.S. SEC give a very lengthy period of infraction for each company, hence the use of five-year period for data extraction.

2. Upon examination of the companies charged with revenue manipulations, we found that all of these companies exhibit very low liquidity with Z-Score $<1$. Therefore, we used Z-Score as a main factor for constructing the opposing sample, used in discriminant analysis. There was a group of companies with ZScore $>3$, composed by Escalada (2011), the financial data of which we used in this research.

The third sample used in this research was the large random sample of companies from U.S. SEC EDGAR. Overall, 20549 statements were downloaded for 6417 companies for the years 2011-2015. Upon the examination of the data some of the statements were discarded due to the fact that they did not contain all required variables. After processing all data only 4516 statements were used. Such significant reduction in the number of usable statement can be attributed partially to the errors in forming the XBRL statements, in part to the fact that not all companies submitted statements in the adjacent years and lastly, the reduction can be attributed to the looseness in the regulations based on U.S. GAAP, which may not require the companies to submit all data required in the described analysis.

First two samples are used in the initial discriminant analysis. The data from both samples was checked for normality and all four variables described by the formulas (2.1)-(2.4) adhere to the Kolmogorov-Smirnov criterion of distribution normality, which is the main condition for the use of discriminant analysis (Pustylnik, 1968). The third sample was checked for the presence of the improbable outlays (the values, which cannot appear in the calculations). The entries, containing such values, were discarded.

\section{RESULTS AND DISCUSSION}

The discriminant analysis performed for the formulas (3.1) and (3.2) yielded the following results for the coefficients $a_{i}$ and $\beta_{i}$

$$
\begin{aligned}
& R=0.150 * X 1+0.924 * X 2 \\
& P=0.367 * Y 1+0.980 * Y 2
\end{aligned}
$$

Both functions allow more than $80 \%$ separation between the samples. However, formula (6.2) gives more symmetrical distinction between the samples and formula (6.1) clearly distinguishes clean sample and gives poorer separation of the entries in the fraud sample. This can be partially attributed to the fact that not all of the entries of the fraud samples contain distinctive manifestations of fraud.

\footnotetext{
${ }^{6}$ Generally accepted accounting principles

${ }^{7}$ Extensible business reporting language
} 
For the fraud sample, calculating boundaries for the cases of joint occurrences using formula (4) gives two intervals $[42 \% ; 59 \%$ ] for cases of $\Delta \mathrm{P}-\Delta \mathrm{R}>0$ coinciding with downward Earnings Management and $[45 \% ; 65 \%$ for $\Delta \mathrm{P}-\Delta \mathrm{R}<0$ coinciding with upward Earnings Management. The probability of $25 \%$ is clearly outside of the calculated intervals, which allows us to state that joint occurrence of two events is not random and we can reject the null hypothesis for the hypothesis stated earlier.

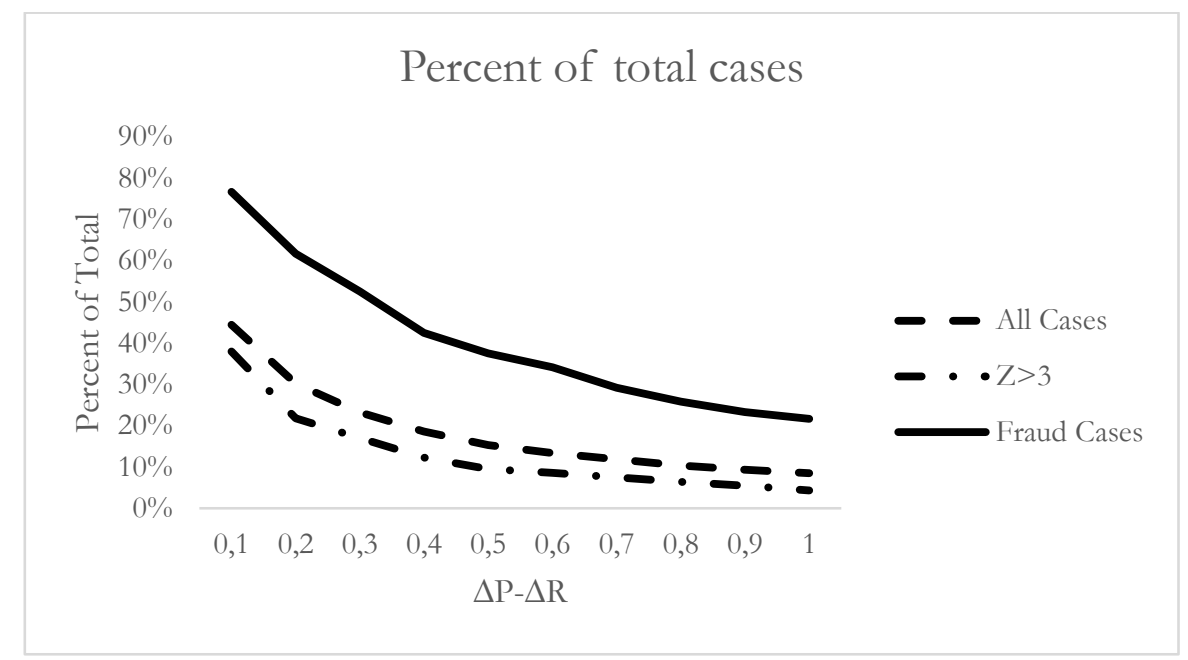

Figure1. Comparison of the numbers of cases of $|\Delta \mathbf{P}-\Delta \mathbf{R}|$ with the total number of available cases

Figure 1 shows the calculations of $|\Delta \mathrm{P}-\Delta \mathrm{R}|$ for various samples (fraud, clean and random). It can be seen that at any value of $|\Delta \mathrm{P}-\Delta \mathrm{R}|$, the percentage of cases in the fraud sample is much higher than in the clean and the random sample. Based on the analysis of the dynamics of the values of $|\Delta \mathrm{P}-\Delta \mathrm{R}|$ we came to the conclusion that $|\Delta \mathrm{P}-\Delta \mathrm{R}|>0.3$ would point towards the existence of a material cases of earnings management in the observed statements The details of the research leading to such conclusion were published in (Pustylnick, 2016).

Following the determination that $\Delta \mathrm{P}-\Delta \mathrm{R} \neq 0$ is a sign of earnings management we proceed with examining the connection between it and the rates of changes of the independent variables. Based on the selected data samples, it was possible to obtain a very interesting set of results. For each sample, we constructed a regression model and performed an analysis of correlation of these variables to each other and to the predictor variables. The following results are presented for each sample separately and then compared to each other.

Table 1

Regression Analysis for Fraud Sample

\begin{tabular}{|c|c|c|c|}
\hline Variable & Coefficient & T-Value & P-Value \\
\hline Constant & -0.0194 & -0.45 & 0.654 \\
\hline$\Delta \mathrm{X} 1$ & -0.0889 & -1.96 & 0.053 \\
\hline$\Delta \mathrm{X} 2$ & -0.6569 & -15.98 & 0.000 \\
\hline$\Delta \mathrm{Y} 1$ & 0.0390 & 0.52 & 0.605 \\
\hline$\Delta \mathrm{Y} 2$ & 1.271 & 8.89 & 0.000 \\
\hline
\end{tabular}


The coverage of the sample $\left(\mathrm{R}^{2}=82.89 \%\right)$ is very high. It can be said that the variables in the described model can with a very high probability predict an outcome. Considering 95\% significance level of the coefficients, we can state that three out of four coefficients are statistically significant. It means that the change in normalized working capital, operating income and revenue fully describe the change in $\Delta \mathrm{P}-\Delta \mathrm{R}$.

Table 2

Correlation between Variables in Fraud Sample

\begin{tabular}{|c|c|c|c|c|}
\hline Variable & $\Delta \mathbf{P}-\Delta \mathbf{R}$ & $\mathbf{\Delta X} 1$ & $\mathbf{\Delta X} 2$ & $\mathbf{\Delta Y 1}$ \\
\hline$\Delta \mathrm{X} 1$ & -0.144 & & & \\
\hline$\Delta \mathrm{X} 2$ & $-0.804^{* * *}$ & 0.114 & & \\
\hline$\Delta \mathrm{Y} 1$ & $-0.280^{* * *}$ & $0.211^{* *}$ & $0.239^{* *}$ & $-0.275^{* * *}$ \\
\hline$\Delta \mathrm{Y} 2$ & $0.528^{* * *}$ & 0.055 & $-0.178^{*}$ & \\
\hline
\end{tabular}

Three stars represent at least 99\% significance, two stars - 95\% and one star - 90\%

Analysis of correlation shows that two variables, representing rate of change of normalized operating income $(\Delta \mathrm{X} 2)$ and normalized revenue $(\Delta \mathrm{Y} 2)$ have a very strong correlation with the resulting variable $\Delta \mathrm{P}$ $\Delta R$. This confirms the earlier findings of Jansen et al. (2012), showing that the appearance of earnings management can be traced to operating margin and assets turnover ratios

The following two tables represent the analysis of the sample, created based on high Z-Score values.

Table 3

Regression Analysis for Clean Sample

\begin{tabular}{|c|c|c|c|}
\hline Variable & Coefficient & T-Value & P-Value \\
\hline Constant & 0.0356 & -0.50 & 0.624 \\
\hline$\Delta \mathrm{X} 1$ & -0.095 & -0.64 & 0.529 \\
\hline$\Delta \mathrm{X} 2$ & -0.4064 & -4.93 & 0.000 \\
\hline$\Delta \mathrm{Y} 1$ & -0.617 & 0.96 & 0.347 \\
\hline$\Delta \mathrm{Y} 2$ & 1.094 & 3.33 & 0.003 \\
\hline
\end{tabular}

The model is still statistically strong, although the coverage is lower, than in the case of 'Fraud' model $\left(\mathrm{R}^{2}=55.65\right)$. It can be partially explained by the small size of the sample and partially by the fact that creation of high Z-Score can be accomplished by different means. Considering the same level of statistical significance of $95 \%$ we can state that only two of the coefficients are statistically significant, namely the coefficient for the rate of growth of normalized operating income and the one for the growth of normalized revenue.

Table 4

Correlation between Variables in Clean Sample

\begin{tabular}{|c|c|c|c|c|}
\hline Variable & $\Delta \mathbf{P}-\Delta \mathbf{R}$ & $\mathbf{\Delta X 1}$ & $\mathbf{\Delta X 2}$ & $\mathbf{\Delta Y 1}$ \\
\hline$\Delta \mathrm{X} 1$ & -0.046 & & & \\
\hline$\Delta \mathrm{X} 2$ & $-0.571^{* * *}$ & 0.016 & & \\
\hline$\Delta \mathrm{Y} 1$ & $-0.292^{*}$ & $0.300^{*}$ & 0.134 & \\
\hline$\Delta \mathrm{Y} 2$ & $0.296^{*}$ & 0.202 & 0.240 & -0.096 \\
\hline
\end{tabular}

Three stars represent at least 99\% significance, two stars - 95\% and one star - 90\% 
The only relatively strong correlation, which has a high statistical significance, is the correlation between $\Delta \mathrm{P}-\Delta \mathrm{R}$ and the rate of growth of normalized operating income. Indeed, the creation of the large Z-Score values requires from the companies to produce high operating income, which is a direct contributor to the company liquidity. There is no evidence of strong correlation between the value of $\Delta \mathrm{P}-\Delta \mathrm{R}$ and rate of growth of all other variables. It proves again that Z-Score does not rely exclusively on the growth of revenue or equity

The third sample, used in this research is the large sample of companies, described previously. The results for this sample are presented in further in this paper.

Table 5

Regression Analysis for Large Random Sample

\begin{tabular}{|c|c|c|c|}
\hline Variable & Coefficient & T-Value & P-Value \\
\hline Constant & -0.0165 & -2.30 & 0.022 \\
\hline$\Delta \mathrm{X} 1$ & -0.0435 & -4.76 & 0.000 \\
\hline$\Delta \mathrm{X} 2$ & -0.8119 & -75.63 & 0.000 \\
\hline$\Delta \mathrm{Y} 1$ & 0.1210 & 7.70 & 0.000 \\
\hline$\Delta \mathrm{Y} 2$ & 0.5636 & 19.87 & 0.000 \\
\hline
\end{tabular}

In this case, all coefficients and the constant are statistically significant with significance level of over $99 \%$. The coverage of the model is also relatively high $\left(\mathrm{R}^{2}=62.63 \%\right)$. It is possible to suggest based on the values of the coefficients that rates of growth of normalized operating income and normalized revenue have the most influence on the changes in the value of $\Delta \mathrm{P}-\Delta \mathrm{R}$.

Table 6

Correlation between Variables in Large Random Sample

\begin{tabular}{|c|c|c|c|c|}
\hline Variable & $\Delta \mathbf{P}-\Delta \mathbf{R}$ & $\mathbf{\Delta X 1}$ & $\mathbf{\Delta X 2}$ & $\boldsymbol{\Delta} \mathbf{Y 1}$ \\
\hline$\Delta \mathrm{X} 1$ & $-0.039^{* *}$ & & & \\
\hline$\Delta \mathrm{X} 2$ & $-0.761^{* * *}$ & -0.005 & & \\
\hline$\Delta \mathrm{Y} 1$ & $-0.046^{* * *}$ & $0.219^{* * *}$ & 0.004 & \\
\hline$\Delta \mathrm{X} 2$ & $-0.028^{*}$ & $-0.051^{* * *}$ & $0.288^{* * *}$ & $-0.097^{* * *}$ \\
\hline
\end{tabular}

Three stars represent at least $99 \%$ significance, two stars $-95 \%$ and one star $-90 \%$

The level of correlation between the variables and $\Delta \mathrm{P}-\Delta \mathrm{R}$ remained very similar. The statistical significance of correlation values improved in many cases, which can be attributed to the size of the sample. There is still a very strong negative correlation between the value of change of normalized operating income and the value of $\Delta \mathrm{P}-\Delta \mathrm{R}$. It can be also noticed that the correlation between the rate of change of all other normalized variables and $\Delta \mathrm{P}-\Delta \mathrm{R}$ is practically non-existent. Based on the statistical analysis it is possible to suggest that in the case of the randomly selected company $\Delta \mathrm{P}-\Delta \mathrm{R}$ is dependent mostly on the rate of change of normalized operating income.

There are two other samples, which may be important from the perspective of researching of earnings management phenomenon. (Pustylnick (2015)) stated that $|\Delta \mathrm{P}-\Delta \mathrm{R}|>0.3$ points towards the presence of significant effort of artificially managing earnings. The case of $\Delta \mathrm{P}-\Delta \mathrm{R}<-0.3$ indicates the upward earnings management and the case of $\Delta \mathrm{P}-\Delta \mathrm{R}>0.3$ indicates downward earnings management. The sizes of the samples carved out of the large random sample are 385 and 354 entries respectively. These cases are further examined here. 
Regression Analysis for Earning Management Samples

\begin{tabular}{|c|c|c|c|c|c|c|}
\hline & \multicolumn{3}{|c|}{ Cases with $\Delta \mathbf{P}-\Delta \mathbf{R}>\mathbf{0 . 3}$} & \multicolumn{3}{c|}{ Cases with $\Delta \mathbf{P}-\Delta \mathbf{R}<-\mathbf{0 . 3}$} \\
\hline Variable & Coefficient & T-Value & P-Value & Coefficient & T-Value & P-Value \\
\hline Constant & 0.3014 & 4.90 & 0.000 & -0.4491 & -5.91 & 0.000 \\
\hline$\Delta \mathrm{X} 1$ & -0.0778 & -1.60 & 0.110 & -0.0269 & -0.56 & 0.578 \\
\hline$\Delta \mathrm{X} 2$ & -0.6485 & -13.76 & 0.000 & -0.6319 & -13.72 & 0.000 \\
\hline$\Delta \mathrm{Y} 1$ & 0.1106 & 1.91 & 0.057 & 0.201 & 1.89 & 0.059 \\
\hline$\Delta \mathrm{Y} 2$ & 0.551 & 4.54 & 0.000 & 0.444 & 3.97 & 0.000 \\
\hline
\end{tabular}

The models for both cases appear to be very similar. The coverage of both models drops $\left(\mathrm{R}^{2}=36.94 \%\right)$ in the case of upwards earnings management and $\left(\mathrm{R}^{2}=34.06 \%\right)$ in the case of downwards earnings management. It appears that the same two coefficients for the rate of growth of normalized operating income and normalized revenue are statistically significant. The models show that in the case of upwards and downwards earnings management the behavior of the observed models is very similar.

Table 8

Correlation between Variables in Earnings Management Samples

\begin{tabular}{|c|c|c|c|c|c|c|c|c|}
\hline & \multicolumn{3}{|c|}{ Cases with $\Delta \mathbf{P}-\Delta \mathbf{R}>\mathbf{0 . 3}$} & \multicolumn{3}{c|}{ Cases with $\Delta \mathbf{P}-\Delta \mathbf{R}<-\mathbf{- 0 . 3}$} \\
\hline Variable & $\Delta \mathrm{P}-\Delta \mathrm{R}$ & $\Delta \mathrm{X} 1$ & $\Delta \mathrm{X} 2$ & $\Delta \mathrm{Y} 1$ & $\Delta \mathrm{P}-\Delta \mathrm{R}$ & $\Delta \mathrm{X} 1$ & $\Delta \mathrm{X} 2$ & $\Delta \mathrm{Y} 1$ \\
\hline$\Delta \mathrm{X} 1$ & $-0.093^{*}$ & & & & 0.072 & & & \\
\hline$\Delta \mathrm{X} 2$ & $-0.571^{* * *}$ & 0.046 & & & $-0.554^{* * *}$ & $-0.132^{* *}$ & & \\
\hline$\Delta \mathrm{Y} 1$ & $-0.109^{* *}$ & $0.238^{* * *}$ & $0.221^{* * *}$ & & 0.013 & $0.399^{* * *}$ & $0.105^{* *}$ & \\
\hline$\Delta \mathrm{X} 2$ & $0.116^{* *}$ & -0.077 & $0.116^{* *}$ & $-0.228^{* * *}$ & $0.080^{*}$ & $-0.091^{*}$ & $0.150^{* * *}$ & -0.012 \\
\hline
\end{tabular}

Three stars represent at least $99 \%$ significance, two stars $-95 \%$ and one star $-90 \%$

The models appear to be very similar. The correlation between $\Delta \mathrm{P}-\Delta \mathrm{R}$ and the rate of growth of the normalized operating income is relatively strong. However, it can also be observed that the correlation between $\Delta \mathrm{P}-\Delta \mathrm{R}$ and the rate of change of normalized revenue is much smaller and not as pronounced as in the fraud sample and even in the 'clean' sample. This observation may lead to the conclusion that in the random case, earnings management may be purer, i.e. related to the manipulations with operating income rather than manipulations with revenue.

By observing the samples, it is possible to make a conclusion that in the case of earnings management, the model has only two variables: rate of change of normalized revenue $(\Delta \mathrm{Y} 2)$ and rate of change of operating income $(\Delta \mathrm{X} 2)$, which bear the most influence in predicting the value of $\Delta \mathrm{P}-\Delta \mathrm{R}$. However, it can be also observed that correlation between the rate of change of normalized revenue and $\Delta \mathrm{P}-\Delta \mathrm{R}$ weakens when the companies are selected at random by the calculated values of $\Delta \mathrm{P}-\Delta \mathrm{R}$. The statistics for the residual $\varepsilon$ in Table 9 are obtained by applying the regression formula for fraud case for the cases of $|\Delta \mathrm{P}-\Delta \mathrm{R}|>0.3$ of the random sample.

Table 9

Descriptive Statistics of the Regression Residual

\begin{tabular}{|c|c|c|c|c|c|}
\hline Case & Mean & Median & St. Dev. & Q1 & Q3 \\
\hline Fraud & 0.2604 & 0.1054 & 0.3865 & 0.0483 & 0.2712 \\
\hline Random $\Delta \mathrm{P}-\Delta \mathrm{R}>0.3$ & 0.5266 & 0.2546 & 0.8153 & 0.1125 & 0.5418 \\
\hline Random $\Delta \mathrm{P}-\Delta \mathrm{R}<-0.3$ & 0.7652 & 0.3674 & 1.1089 & 0.1308 & 0.9154 \\
\hline
\end{tabular}


The values of the residual in the case of downward earnings management (positive $\Delta \mathrm{P}-\Delta \mathrm{R}$ ) are lower than in the case of upward earnings management (negative $\Delta \mathrm{P}-\Delta \mathrm{R}$ ). For both of them, we can say that the difference between calculated value of $\Delta \mathrm{P}-\Delta \mathrm{R}$ and predicted value of $\Delta \mathrm{P}-\Delta \mathrm{R}$ is significantly higher than in the case of fraud sample. It is possible to suggest that values of residual exceeding 0.5 would prompt that the manipulations were likely performed using fraudulent expense recognition rather than fraudulent revenue recognition.

The analysis of the regression models in this section revealed a very interesting recurring fact. All values of $\Delta \mathrm{P}-\Delta \mathrm{R}$ correlate strongly with the rates of change of the operating margin. This can be an indirect proof that the observed models describe earnings management. The negative sign of the correlation factor corresponds well with the previous findings that pairing of $\Delta \mathrm{P}-\Delta \mathrm{R}>0$ and downward earnings management and $\Delta \mathrm{P}-\Delta \mathrm{R}<0$ and upward earnings management are not coincidental.

\section{CONCLUSIONS}

This research develops the mechanism of detection of earnings management, which is independent of the type of earnings management applied to the statements. It allows practitioners detecting the earnings management presence and roughly estimating its severity. The results show that the sign of $\Delta \mathrm{P}-\Delta \mathrm{R}$ points towards which earnings management was detected (upward or downward) and the value of $|\Delta \mathrm{P}-\Delta \mathrm{R}|$ indicates its severity.

The further observations of the behavior of the variables comprising $\Delta \mathrm{P}-\Delta \mathrm{R}$ made in this research can prompt the conclusion that in the case of all four samples rate of change of the normalized operating income has the most influence on the value of $\Delta \mathrm{P}-\Delta \mathrm{R}$. The rate of change of normalized operating income (or operating earnings) can be viewed as a primary indicator of earnings management. The negative correlation between the rate of change of operating income and $\Delta \mathrm{P}-\Delta \mathrm{R}$ shows that high $\Delta \mathrm{P}-\Delta \mathrm{R}$ can be viewed as an indicator of earnings management.

Examination of the residual of the formula obtained from the fraud sample shows that random companies with high $\Delta \mathrm{P}-\Delta \mathrm{R}$ are more likely to manipulate with expenses, leaving revenue constant (or changing slightly). Therefore, high differential between the values of $\Delta \mathrm{P}-\Delta \mathrm{R}$ calculated using the formulas (6.1) and (6.2) and the values calculated by the regression formula, obtained for the fraud sample, can indicate that recognition of expenses is the most likely cause of the appearing signs of earnings management.

This conclusion can play a significant role in the practice application of the algorithm of calculation of $\Delta \mathrm{P}-\Delta \mathrm{R}$. The auditor, obtaining such high absolute value of $\Delta \mathrm{P}-\Delta \mathrm{R}$, may also look at the differential between two calculated values and have an indication of the direction of further examination of the paperwork in the case when earnings management is suspected. However, it is necessary to state that the research presents the results obtained using statistical analysis. Although these results have high statistical significance, the errors and misclassification is possible, especially in the borderline cases.

At the beginning of this paper it was mentioned that major efforts of detection of earnings management are directed towards recognizing real and accrual based earnings management. The efforts in these directions are completely separate from each other by the selection of variables and the interpretation of the results. We believe that using the method described in this can give results, which will allow practical detection of earnings management.

As many other research methods, the method offered in this paper is based on the statistical analysis of the financial information. It is absolutely possible that the signs of earnings management may appear as a result of the exceptional operational excellency or absolutely disastrous circumstances surrounding the 
reporting period for the certain enterprise. This argument is absolutely valid and is very similar to argument stated by Gerakos (2012) that non-discretional accruals can change between periods due to operating reasons. Hence any statistical analysis is not $100 \%$ correct and can serve as cause for concern and not as indictment.

\section{REFERENCES}

Achleitner, A.-K., Günther, N., Kaserer, C., \& Siciliano, G. (2014). Real Earnings Management and Accrual-based Earnings Management in Family Firms. European Accounting Review, 23(3), 431-461. doi:10.1080/09638180.2014.895620

Alexeev, M., \& Kim, S. (2008). The Korean financial crisis and the soft budget constraint. Journal of Economic Behavior \& Organization, 68(1), 178-193.

Alhadab, M., Clacher, I., \& Keasey, K. (2016). A Comparative Analysis of Real and Accrual Earnings Management around Initial Public Offerings under Different Regulatory Environments. Journal of Business Finance \& Accounting, 43(7-8), 849-871.

Altman, E. (1968). Financial Ratios, Discriminant Analysis and the Prediction of Corporate Bankruptcy. Journal of Finance. doi:10.1111/j.1540-6261.1968.tb00843.x

Austin, B. J., Haskins, M. E., Ferris, K. R., Sack, R. J., \& Allen, B. R. (2000). Financial Accounting and Reporting. Second Canadian Edition. Toronto, ON, Canada: McGraw-Hill.

Bauman, M. P. (2014). Forecasting operating profitability with DuPont analysis: Further evidence. Review of Accounting and Finance, 13(2), 191-205.

Beneish, M. (1997). Detecting GAAP violation: implications for assessing earnings management among firms with extreme financial performance. Journal of Accounting and Public Policy, 16(3), 271-309. doi: http://dx.doi.org/10.1016/S0278-4254(97)00023-9

Beneish, M. (2001). Earnings Management: A Perspective. Managerial Finance, 27(12), 3-17. doi: DOI:

Beneish, M., Press, E., \& Vargus, M. E. (2012). Insider Trading and Earnings Management in Distressed Firms. Contemporary Accounting Research, 29(1), 191-220.

Bruns, W. J., \& Merchant, K. A. (1990). The Dangerous Morality of Managing Earnings. Management Accounting, 72(2), 22-25.

Dechow, P. M., Ge, W., Larson, C. R., \& Sloan, R. G. (2011). Predicting Material Accounting Misstatements. Contemporary Accounting Research, 28(1), 17-82.

Dechow, P. M., Hutton, A. P., Kim, J. H., \& Sloan, R. G. (2012). Detecting Earnings Management: A New Approach. Journal of Accounting Research, 50(2), 275-334. doi:10.1111/j.1475-679X.2012.00449.x

Dechow, P. M., \& Skinner, D. J. (2000). Earnings Management: Reconciling the Views of Accounting Academics, Practitioners and Regulators. Accounting Horizons, 14(2), 235-250. doi: DOI: http://dx.doi.org/10.2308/acch.2000.14.2.235

Dechow, P. M., Sloan, R. G., \& Sweeney, A. P. (1995). Detecting Earnings Management. The Accounting Review, 70(2), 193-225. doi:

Escalada, J. (2011). 45 Dividend Stocks With Good Credit Scores. Retrieved August 29,2012, from http:/ / seekingalpha.com/article/307563-45-dividend-stocks-with-good-credit-scores

Ferrer, R. C., \& Ferrer, G. J. (2016). Earnings management indicators and their impact on inventory turnover under food, beverage and tobacco sector: a thorough study using simultaneous equations model. Academy of Accounting \& Financial Studies Journal, 20(2), 93-103.

Fess, P. E., \& Warren, C. S. (1993). Accounting Principles, 17e. Cincinnati, OH: South-Western Publishing Co.

Gerakos, J. (2012). Discussion of Detecting Earnings Management: A New Approach. Journal of Accounting Research, 50(2), 335-347. doi:10.1111/j.1475-679X.2012.00452.x

Jansen, I. P., Ramnath, S., \& Yohn, T. L. (2012). A Diagnostic for Earnings Management Using Changes in Asset Turnover and Profit Margin. Contemporary Accounting Research, 29(1), 221-251. doi:10.1111/j.19113846.2011.01093.x 
Jones, J. J. (1991). Earnings Management Following Import Relief Investigations. Journal of Accounting Research, 29(2), 193-228. doi:10.2307/2491047

Kirkos, E., Spathis, C., \& Manopoulos, Y. (2007). Data Mining techniques for the detection of fraudulent financial statements Expert Systems with Applications, 92(4), 995-1003.

Lang, M., Smith Raedy, J., \& Wilson, W. (2006). Earnings management and cross listing: Are reconciled earnings comparable to US earnings? Journal of Accounting and Economics, 42(1-2), 255-283. doi:10.1016/j.jacceco.2006.04.005

Leggett, D. M., Parsons, L. M., \& Reitenga, A. L. (2016). Real Earnings Management and Subsequent Operating Performance. IUP Journal of Operations Management, 15(4), 7-32.

Lenard, M. J., \& Alam, P. (2009). An Historical Perspective on Fraud Detection: From Bankruptcy Models to Most Effective Indicators of Fraud in Recent Incidents. Journal of Forensic \& Investigative Accounting, Vol 1, Iss 1.

Marzcewski, D. C., \& Akers, M. D. (2005). CPA's Perception on the impact of SAS 99. CPA Journal, 75(6), 38-40.

McKee, T. E. (2005). Earnings Management: An Executive Perspective, 1st Edition: Cengage Learning.

Park, Y. W., \& Shin, H.-H. (2004). Board composition and earnings management in Canada. Journal of Corporate Finance, 10(3), 431-457.

Persons, O. A. (2011). Using Financial Statement Data to Identify Factors Associated with Fraudulent Financial Reporting. Journal of Applied Business Research, 11(3).

Pustylnick, I. (2016). Using Z-Score in detection of revenue manipulations. Paper presented at the 21-st International Scientific Conference Economics and Management, Brno, Czech Republic. Retrieved from: http://icem.lt/public/icem/ICEM_2016.pdf

Pustylnik, E. I. (1968). Statistical methods of analisys and processing of observations. Moscow: Nauka Publishing.

Roychowdhury, S. (2006). Earnings management through real activities manipulation. Journal of Accounting and Economics, 42(3), 335-370. doi:10.1016/j.jacceco.2006.01.002

Spathis, C. (2002). Detecting false financial statements using published data: some evidence from Greece. Managerial Auditing Journal, 17(4), 179-191.

Taylor, G. K., \& Xu, R. Z. (2010). Consequences of real earnings management on subsequent operating performance. Research in Accounting Regulation, 22(2), 128-132.

Tsipouridou, M., \& Spathis, C. (2014). Audit opinion and earnings management: Evidence from Greece. Accounting Forum, 38(1), 38-54. doi:10.1016/j.accfor.2013.09.002

Urri, M. (2002, July 10). Those US scandals couldnt happen here... could they?: Stricter accounting standards make another enron less likely in the UK, reports maggie urry. but vigilance is still needed. Financial Times, 25-25. 